\title{
RESÍDUOS SÓLIDOS DE CURTUMES COMO ADSORVENTES PARA A REMOÇÃO DE CORANTES EM MEIO AQUOSO
}

Rogério Marcos Dallago* e Alessandra Smaniotto

Departamento de Química, Universidade Regional Integrada do Alto Uruguai e Missões, Av. Sete de Setembro, 1621, 99700-000 Erechim - RS

Luiz Carlos Alves de Oliveira

Departamento de Química, Universidade Federal de Lavras, CP 1 37, 37200-000 Lavras - MG

Recebido em 5/4/04; aceito em 9/9/04; publicado na web em 4/2/05

\begin{abstract}
SOLID WASTE FROM TANNERIES AS ADSORBENT FOR THE REMOVAL OF DYES IN AQUEOUS MEDIUM. The tanning process in the leather industry generates very high quantities of chromium-containing solid waste ("wet blue" leather). Environmental concerns and escalating landfill-costs are becoming increasingly serious problems for the leather industry and an alternative disposal is needed. In this work, we are presenting a novel application for this solid waste, which is the removal of organic contaminants from aqueous-solution. The adsorption isotherm of "wet blue" leather waste from the AUREA tanning company in Erechim-RS (Brazil) showed that this material presents high adsorption capacities of the reactive textile dyes.
\end{abstract}

Keywords: "wet blue" leather; contaminated effluents; adsorption process.

\section{INTRODUÇÃO}

A origem dos corantes têxteis é incerta, mas há indicações de seu uso pelo homem desde os primórdios das civilizações. No Egito, muitos dos tecidos encontrados em múmias eram coloridos. No Brasil, desde seu descobrimento, sua história tem estado relacionada à produção de corantes. A começar pelo seu nome, uma vez que este é proveniente da madeira "Pau Brasil", do qual era extraído um pigmento capaz de tingir tecidos com cores fortes, como vermelho, rosa ou marrom ${ }^{1}$.

Atualmente, aproximadamente 10.000 corantes são produzidos em escala industrial. Destes, cerca de 2.000 encontram-se disponíveis para a indústria têxtil. No Brasil, das aproximadamente 20 t/ano de corantes consumidos pela indústria têxtil, cerca de $20 \%$ são descartados como efluentes. A principal fonte desta perda corresponde à fixação incompleta dos corantes à fibra durante o processo de tingimento ${ }^{2-4}$.

Do ponto de vista ambiental, a remoção da cor dos efluentes é um dos grandes problemas enfrentados pelo setor têxtil. A elevada estabilidade biológica dos corantes dificulta sua degradação pelos sistemas de tratamento convencionais (normalmente lodo ativo) empregados pelas indústrias têxteis. A contaminação de rios e lagos com estes compostos provoca, além da poluição visual, sérios danos à fauna e flora destes locais. Com suas intensas colorações, os corantes restringem a passagem de radiação solar, diminuindo a atividade fotossintética natural, provocando alterações na biota aquática e causando toxicidade aguda e crônica destes ecossistemas ${ }^{5-9}$.

Devido a estas implicações ambientais, novos processos de remoção e/ou degradação destes compostos em efluentes têxteis têm sido testados ${ }^{10}$. Os processos oxidativos, como o tratamento com ozônio $^{11-14}$, fotocatálise heterogênea ${ }^{15-17}$ e via sistema Fenton ${ }^{18}$, baseiam-se no emprego de agentes oxidantes destinados a acelerar a degradação destes compostos. No entanto, estes processos considerados destrutivos apresentam alguns inconvenientes. O ozônio, em

*e-mail: dallago@uri.com.br alguns casos, dependendo da composição química do efluente pode conduzir à formação de intermediários com maior grau de toxicidade $^{10,12}$. A fotocatálise heterogênea apresenta as principais limitações vinculadas às fontes artificiais de radiação, à dificuldade de sua penetração no meio reacional e à remoção dos fotocatalisadores empregados.

Outros processos visando a eliminação desses contaminantes, como a adsorção, encontram maior aplicação industrial, pois associam baixo custo e elevadas taxas de remoção. Além disto, em alguns casos, por não se tratar de um método destrutivo, possibilita a recuperação do corante sem perda de sua identidade química ${ }^{19,20}$. Atualmente o material que apresenta maior capacidade de adsorção, sendo amplamente utilizado para o tratamento de efluentes, é o carvão ativado. Entretanto, devido às perdas durante o processo de recuperação do adsorvente, sua utilização torna-se onerosa. Além disso, em função de sua superfície ser quimicamente positiva, a adsorção de corantes de caráter catiônico é limitada ${ }^{21}$.

Neste sentido, existe um crescente interesse pela busca de materiais alternativos de baixo custo que possam ser utilizados, em substituição ao carvão ativado, como adsorventes para a eliminação de corantes têxteis, tais como $\operatorname{argilas}^{22,23}$, bagaço de cana ${ }^{24}$, madeira $^{25} \mathrm{e}$ outros resíduos celulósicos ${ }^{26,27}$.

A indústria do couro produz uma grande quantidade de resíduos sólidos oriundos do processo de beneficiamento do couro com cromo, para a obtenção do couro "wet blue". Uma parte considerável desse couro é perdida na forma de "serragens" e "aparas" que devem ser descartadas em aterros especiais, para evitar o lixiviamento do cromo para o meio ambiente. Processos alternativos visando a reciclagem do cromo estão sendo estudados. Estes processos, em sua grande maioria, baseiam-se na degradação da fase orgânica (couro), a qual pode ser obtida química ${ }^{28,29}$ ou termicamente (incineração) ${ }^{30-33}$.

Neste trabalho foi utilizado, pela primeira vez, o couro residual "wet blue" como material adsorvente de corantes têxteis em soluções aquosas. Para tanto, foram utilizadas como moléculas modelo os corantes têxteis Vermelho Drimarem X6BN, Amarelo Cibacrone, Azul Procion e Indigo (Tabelas 1 e 2). 
Tabela 1. Valores de capacidade de adsorção pelos diferentes materiais empregados como adsorventes e constante de velocidade (k) para o couro "wet blue"

\begin{tabular}{lcccc}
\hline Corante & \multicolumn{3}{c}{ Adsorventes } \\
\hline & Carvão Ativado $(\mathrm{mg} / \mathrm{g})$ & Couro "wet blue" $(\mathrm{mg} / \mathrm{g})$ & $\mathrm{k}\left(\mathrm{min}^{-1}\right)$ & Couro Natural $(\mathrm{mg} / \mathrm{g})$ \\
\hline Vermelho Drimarem & 29,15 & 121,4 & 0,0113 & 92,0 \\
Amarelo Cibacrone & 129,6 & 135,4 & 0,0158 & 32,8 \\
Azul Procion & 0 & 118,8 & 0,0031 & 36,3 \\
Indigo & 164,6 & 109,8 & 0,0199 & 78,1 \\
\hline
\end{tabular}

* A concentração das soluções de corantes foi de $500 \mathrm{mg} \mathrm{L}^{-1}$

\section{PARTE EXPERIMENTAL}

\section{Material}

Os materiais adsorventes couro "wet blue" e couro natural, na forma de serragem, foram disponibilizados pelo curtume AUREA, localizado na região de Erechim-RS. O couro "wet blue" caracteriza-se por apresentar um teor de cromo de aproximadamente $20 \mathrm{~g} \mathrm{~L}^{-1}$. O teor de cromo no couro "wet blue" foi determinado por espectroscopia de absorção atômica (Modelo Spectra AA 55, marca Varian).

Os corantes Vermelho Drimarem, Amarelo Cibacrone, Azul Procion e Indigo foram fornecidos pela empresa NEWCO Comercio e Representações Ltda, Diadema - SP.

\section{Testes de adsorção}

Os testes de capacidade de adsorção foram feitos em bateladas a partir de soluções dos corantes nas concentrações de 10, 50, 100, 800 e $1000 \mathrm{mg} \mathrm{L}^{-1}$. Os experimentos foram realizados à temperatura ambiente $\left(25^{\circ} \mathrm{C}\right)$ e pH 5,5. Para a obtenção das isotermas de adsorção, as soluções $(30 \mathrm{~mL})$ foram deixadas em contato com os materiais adsorventes $(\approx 0,1 \mathrm{~g})$, sob agitação mecânica, por um período de 24 h. A adsorção foi acompanhada por espectrofotometria UV-Vis (Agilent, modelo 8453), monitorando-se a absorção dos corantes nos seguintes comprimentos de onda $\left(\lambda_{\text {máx. }}\right): 425 \mathrm{~nm}$ para o Amarelo Cibacrone, $543 \mathrm{~nm}$ para o Vermelho Drimarem e $610 \mathrm{~nm}$ para os corantes Azul Procion e Indigo.

Também foram realizados testes de adsorção utilizando carvão ativado (ALDRICH), para fins de comparação.

Os ensaios cinéticos foram conduzidos nas mesmas condições experimentais, em termos de massa $(0,1 \mathrm{~g})$, volume de solução (30 $\mathrm{mL})$, temperatura $\left(25^{\circ} \mathrm{C}\right)$ e $\mathrm{pH}$, descritas para os ensaios de adsorção. A concentração das soluções de corantes foi de $800 \mathrm{mg} \mathrm{L}^{-1}$.

\section{RESULTADOS E DISCUSSÃO}

A Figura 1 apresenta os espectros de absorção obtidos para os corantes Vermelho Drimarem, Amarelo Cibacrone e Azul Procion. A ausência do espectro do corante Indigo deve-se ao fato de sua similaridade com o obtido para o Azul Procion.

Com base nos espectros de absorção (Figura 1) optou-se pelos comprimentos de ondas $\left(\lambda_{\text {máx. }}\right)$ mais adequados para cada corante: 425 para o Amarelo Cibacrone, $543 \mathrm{~nm}$ para o Vermelho Drimarem e $610 \mathrm{~nm}$ para o Azul Procion.

\section{Ensaios de adsorção}

A capacidade de adsorção dos couros "wet blue" e natural para os corantes Vermelho Drimarem, Amarelo Cibacrone, Azul Procion e Indigo foi avaliada mediante isotermas de adsorção, as quais foram

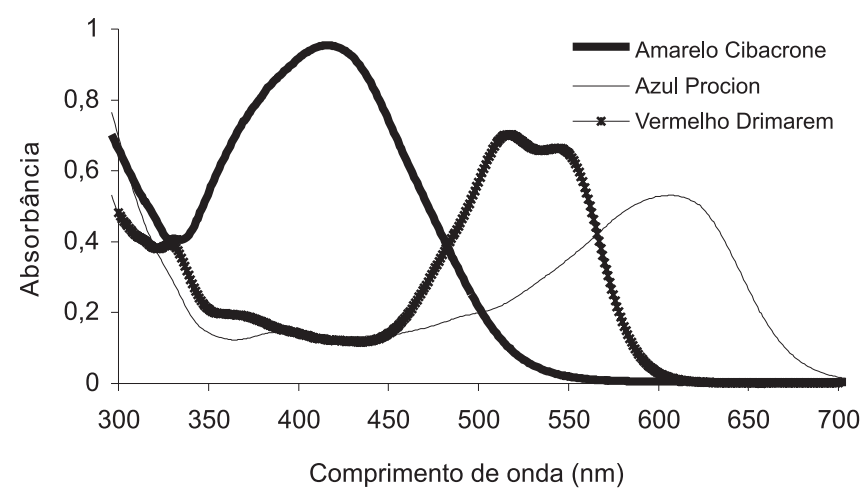

Figura 1. Espectros de adsorção dos corantes (50 $\mathrm{mg} \mathrm{L}^{-1}$ ) Amarelo Cibacrone, Vermelho Drimaren e Azul Procion na região visível do espectro

obtidas à temperatura ambiente e pH 5,5. A forma apresentada pelas isotermas de adsorção segue o modelo de Langmuir ${ }^{34}$.

A Figura 2 apresenta as isotermas de adsorção obtidas para o corante Amarelo Cibacrone.

Os resultados demonstram que o couro curtido "wet blue" apresentou maior capacidade de adsorção quando comparado ao couro natural.

Esta tendência (adsorção, "wet blue" $>>$ adsorção ${ }_{\text {natural }}$ ) foi observada para todos os corantes estudados (Tabela 1). As diferenças mais significativas foram observadas para os corantes Amarelo Cibacrone e Azul Procion(> 300\%). Essas diferenças observadas na capacidade de adsorção dos diferentes corantes devem estar vinculadas às particularidades estruturais de cada corante, como por exemplo o número de sítios de caráter aniônico (-SO ${ }_{3}^{-}$) (Tabela 2). Os corantes Amarelo Cibacrone e Azul Procion apresentam em suas estruturas um número maior destes sítios ( 3 sítios $\mathrm{SO}_{3}^{-}$) em relação aos demais corantes (2 sítios $\mathrm{SO}_{3}^{-}$).

A retenção dos corantes pelos materiais adsorventes envolve várias forças atrativas, como interação iônica, forças de van der Waals,

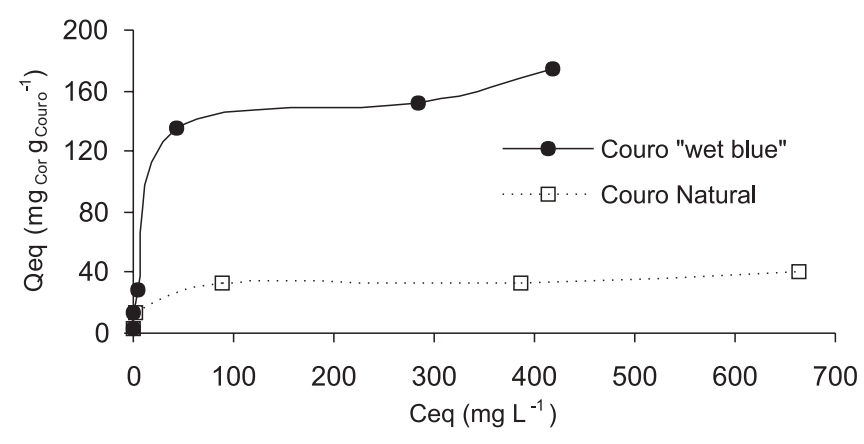

Figura 2. Isotermas de adsorção dos couros "wet blue" e natural para o corante Amarelo Cibacrone 
Tabela 2. Caracteristícas dos corantes utilizados

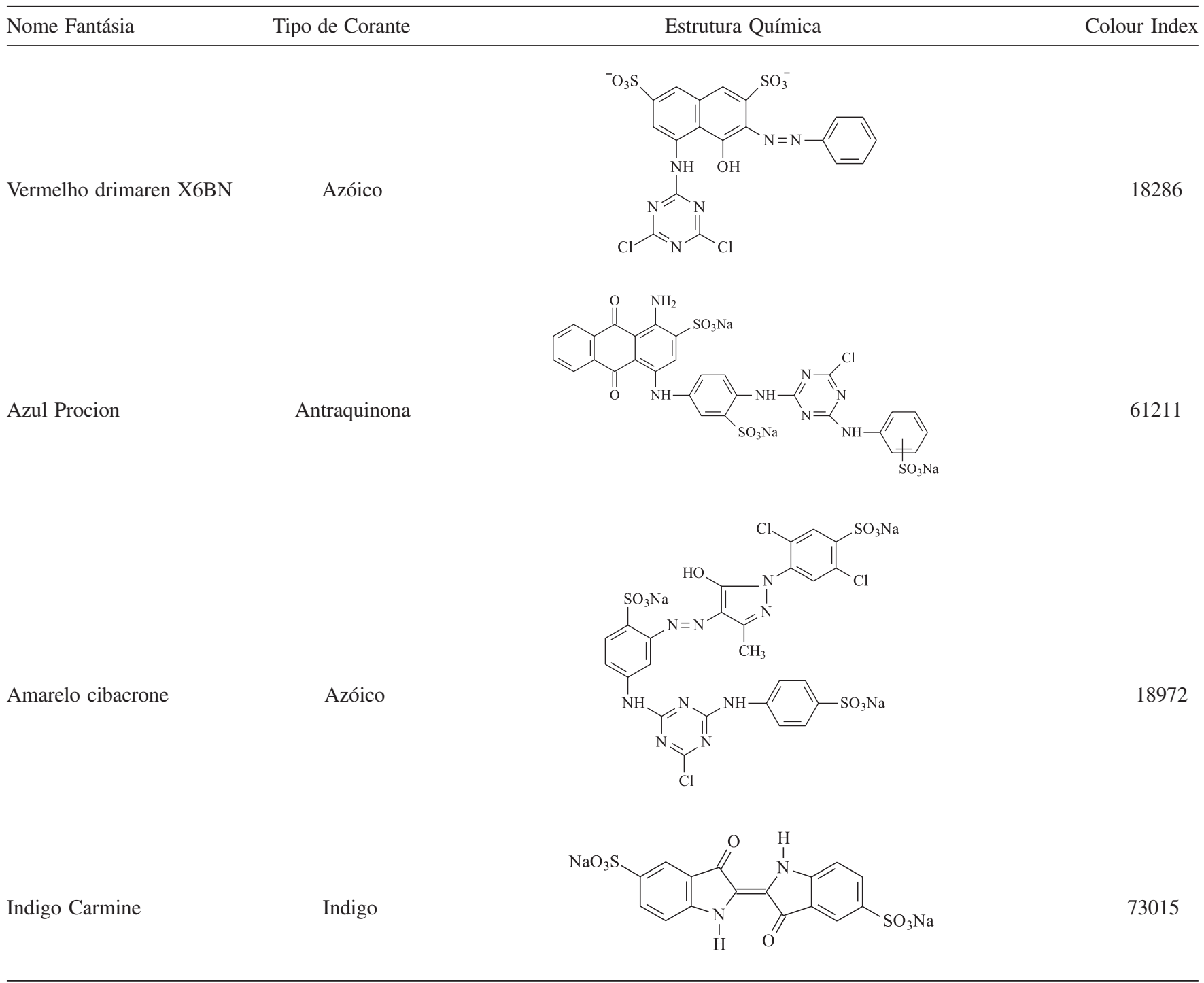

ligações de hidrogênio e ligações covalentes. Dependendo do tipo de corante, uma ou mais forças vão atuar sobre o processo de fixação ${ }^{1,35}$. Nos corantes ácidos, devido ao caráter aniônico, a interação com a fibra (natural ou sintética) ocorre, preferencialmente, através de uma troca iônica. Nos corantes reativos, devido ao grupo eletrofílico, a principal forma de interação com a fibra se dá por ligações covalentes. No entanto, devido à presença de grupos sulfonatos, esta classe de corantes apresenta também caráter aniônico, responsável por interações de caráter eletrostático.

O couro, assim como a lã e a seda, é um material constituído por longas cadeias poliméricas de monômeros de alfa-amino-ácidos $\left\{\mathrm{RCH}\left(\mathrm{NH}_{2}\right) \mathrm{COOH}\right.$, onde $\mathrm{R}$ é um grupo orgânico $\}$, unidos por ligações amídicas (-CO-NH-). As características químicas destes grupos, como hidrofilicidade, hidrofobicidade, acidez ou basicidade, servem como possíveis sítios de interações entre o material adsorvente e os corantes ${ }^{1}$.

O couro natural, devido à sua composição química, centros positivos - referentes aos grupos amino $\left(-\mathrm{NH}_{3}^{+}\right)$, e negativos - referentes aos carboxilatos (-COO-), presentes em sua estrutura protéica é capaz de atrair eletrostaticamente os corantes. O couro "wet blue" difere, em relação ao couro natural, somente pela presença do cromo. O couro "wet blue" apresenta um teor de cromo de $20 \mathrm{~g} \mathrm{~L}^{-1}$. Sua função é de atuar como ponte, interligando os grupos protéicos do couro $^{36}$, proporcionando maior estabilidade química e mecânica ao produto final ${ }^{28}$. A presença do cromo, com seu caráter positivo, mesmo após sua complexação com a rede proteica do $\operatorname{couro}^{36}$ (Figura 3), amplia as possibilidades de interações iônicas entre o couro "wet blue" e os corantes, principalmente os de caráter aniônico, proporcionando maior capacidade de adsorção, como a observada para os corantes estudados (Tabela 1).



Figura 3. Rede estrutural do couro após o processo de curtimento (Couro "wet blue")

Estudos realizados de adsorção empregando couros com distintos teores de cromo incorporado à rede protéica $(0,0,7$ e $2 \%$ em massa) evidenciaram que sua capacidade de adsorção para o corante Vermelho Drimarem aumentava proporcionalmente com a concentração de $\mathrm{cromo}^{37}$. 
Para o couro "wet blue" todos os corantes apresentaram valores de capacidade de adsorção similares (Figura 4). O mesmo não foi observado para o couro natural, que apresentou diferenças significativas de adsorção entre os corantes (Figura 5). Sem o cromo, a capacidade adsortiva do couro pelos corantes fica restrita à influência dos grupos amino $\left(-\mathrm{NH}_{3}{ }^{+}\right)$da rede proteica do couro. Fator este que, como visto anteriormente, influencia diretamente em sua capacidade adsortiva (adsorção, ${ }_{\text {wet blue" }}>>$ adsorção ${ }_{\text {natural }}$ ). Com menor capacidade adsortiva, as oscilações nos valores de adsorção tornam-se mais significativas (Figura 5). Por outro lado, na presença do cromo (couro "wet blue"), a magnitude destas variações é minimizada pelas elevadas quantidades de corante adsorvido (Figura 4).

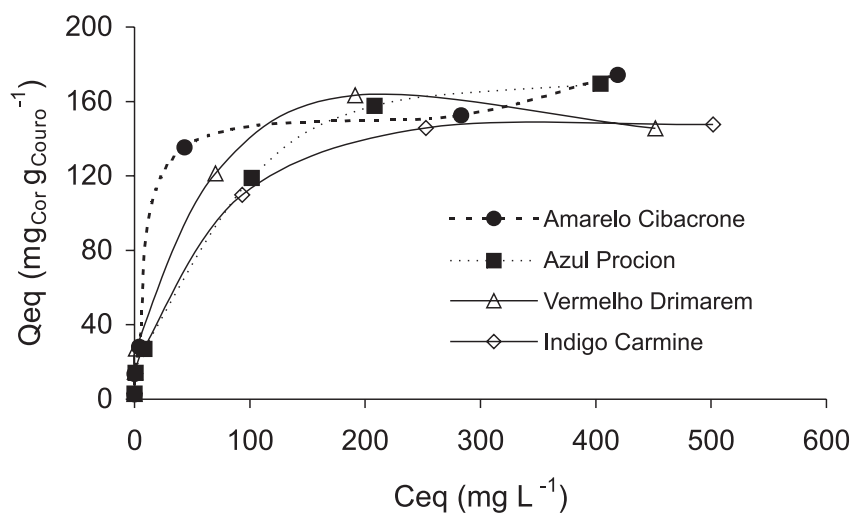

Figura 4. Isotermas de adsorção à temperatura ambiente para o couro "wet blue"

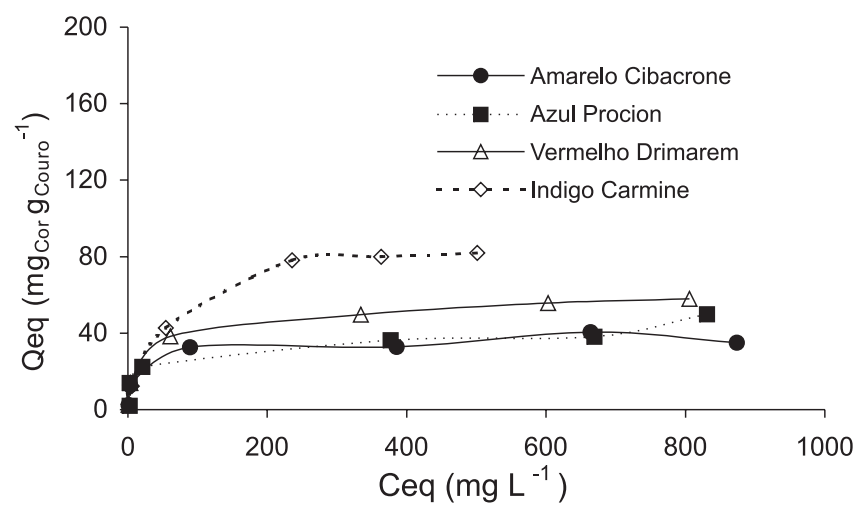

Figura 5. Isotermas de adsorção à temperatura ambiente para o couro natural

\section{Influência do pH}

A influência do pH na capacidade de adsorção foi realizada com o couro "wet blue" para todos os corantes, utilizando como parâmetros os seguintes valores de $\mathrm{pH}: 3,0 ; 7,0$ e 9,5.

Os resultados experimentais relativos à capacidade de adsorção em função do pH (Figura 6) indicam uma influência desta propriedade no processo envolvendo os corantes Índigo Carmine, Vermelho Drimarem e Amarelo Cibacrone, sendo inexpressivo para o corante Azul Procion. Em pH 3 observou-se os melhores resultados, ou seja, os maiores valores de capacidade de adsorção de corante pelo couro "wet blue". A acidez do meio $(\mathrm{pH})$ afeta o equilíbrio químico dos grupos iônicos (forma dissociada $\leftrightarrow$ forma molecular) presentes tanto no adsorvente $\left(-\mathrm{NH}_{3}{ }^{+}\right.$e $\left.-\mathrm{COO}^{-}\right)$como no adsorvato $\left(-\mathrm{SO}_{3}^{-}\right)$, influenciando em suas interações de caráter eletrostático. Valores de $\mathrm{pH}$ menores que o $\mathrm{pH}$ referente ao ponto isoelétrico (equilíbrio de cargas) do couro "wet blue" (P.I. = pH 6) ${ }^{36}$ conduzem a um aumento

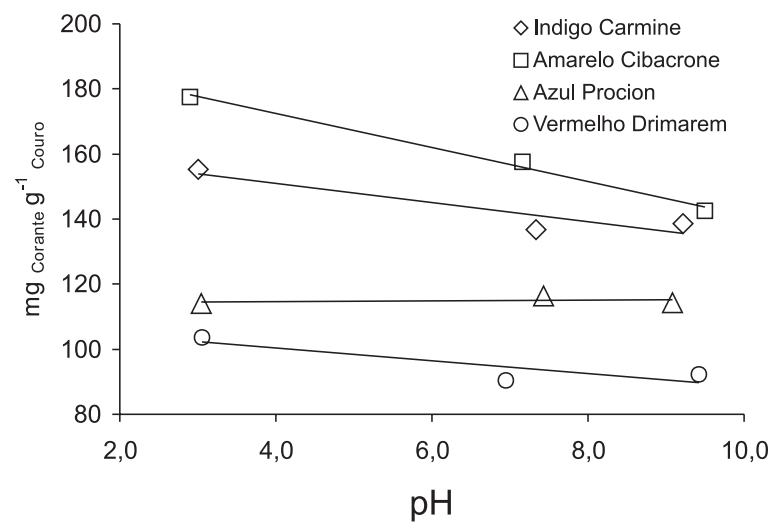

Figura 6. Relação entre a capacidade de adsorção do couro "wet blue" em função do $\mathrm{pH}$

significativo de seu caráter catiônico, mediante dissociação dos grupos amino $\left(-\mathrm{NH}_{3}^{+}\right)$presentes em sua rede proteica, favorecendo a adsorção dos corantes de caráter aniônico. Este efeito é potencializado pelo deslocamento do equilíbrio químico dos grupos carboxílicos (aniônicos), presentes no couro, para sua forma molecular (-COOH). A diminuição da adsorção em meio alcalino $(\mathrm{pH}=9,5)$ justifica-se pela redução do número de grupos $-\mathrm{NH}_{3}{ }^{+}$no adsorvente, diminuindo a interação entre estes e os grupos $-\mathrm{SO}_{3}{ }^{-}$dos corantes.

\section{Ensaio de lixiviação do cromo}

Após os ensaios de adsorção, as amostras foram submetidas à análise do teor de cromo presente na solução aquosa, por espectroscopia de absorção atômica. Para todas as soluções analisadas não foi constatada a presença de cromo, o que evidencia a inexistência da lixiviação de cromo do material adsorvente para a fase aquosa. Estes resultados sugerem que todo o cromo presente no couro "wet blue" encontra-se complexado com a rede proteica do couro.

\section{Ensaio cinético}

A cinética de adsorção para os couros natural e "wet blue" foi avaliada somente para o corante Vermelho Drimarem (Figura 7). O gráfico sugere uma dependência de primeira ordem em relação à concentração dos sítios adsorventes na superfície do couro, com uma

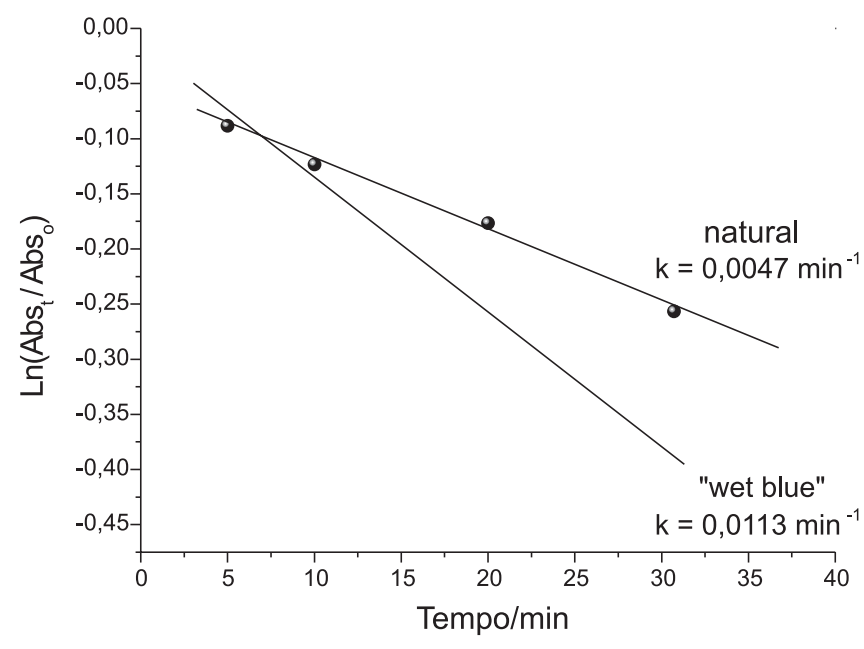

Figura 7. Cinética de adsorção do Vermelho Drimarem para os couros "wet blue" e natural 
constante de velocidade (k) de 0,0113 e 0,0047 $\mathrm{min}^{-1}$ para os couros "wet blue" e natural, respectivamente.

A cinética de adsorção para os demais corantes foi avaliada somente para o couro "wet blue" (Tabela 1 - coluna 4), uma vez que a relação entre as cinéticas de adsorção dos dois couros independe do corante (todos os corantes estudados apresentam, devido à presença de grupos sulfônicos (- $\left.\mathrm{SO}_{3} \mathrm{Na}\right)$, o mesmo tipo de interação preferencial com o adsorvente - troca iônica). Ou seja, os valores de k observados para o couro "wet blue" serão maiores que os observados para o couro natural.

\section{Ensaios comparativos}

Para fins de comparação foram realizados ensaios de adsorção empregando como material adsorvente o carvão ativado (Aldrich). Os ensaios foram conduzidos nas mesmas condições experimentais descritas para os materiais adsorventes avaliados.

Para todos os corantes o couro "wet blue" apresentou uma capacidade de adsorção no mínimo similar à do carvão ativado, um adsorvente amplamente utilizado no tratamento de efluentes têxteis. Para dois corantes (Vermelho Drimarem e o Azul Procion) o couro "wet blue" apresentou uma capacidade de adsorção significativamente superior (Tabela 1).

\section{Destino do couro "wet blue" contendo o corante adsorvido}

Evidenciada a elevada capacidade de adsorção apresentada pelo resíduo industrial (couro "wet blue"), surge uma importante questão: o que fazer com o couro contendo o corante adsorvido? Como mencionado, atualmente existem alguns processos empregados na eliminação do farelo de rebaixadeira (serragens) do couro "wet blue" gerado nos curtumes. $\mathrm{O}$ processo mais comumente empregado é sua disposição em aterros industriais, o que, além de ser um procedimento oneroso, não elimina o problema. Outro procedimento estudado para a eliminação destes resíduos sólidos baseia-se nas hidrólises ácida ou básica. Além destas alternativas, alguns pesquisadores ${ }^{31-33}$ estão propondo incineração controlada (temperatura de queima e conposição do combustível) deste material, visando a obtenção de uma cinza rica em óxido de cromo, passível de ser reutilizada pelos curtumes, em novos processos de curtimento.

\section{CONCLUSÕES}

A parte inovadora deste trabalho consiste no emprego de resíduos sólidos provenientes do processo de curtimento do couro (serragens e aparas), sérios poluentes ambientais, para a remoção de corantes dos efluentes da indústria têxtil. Estes resíduos, encontrados abundantemente nos curtumes, apresentaram elevada capacidade de adsorção, similar à do carvão ativado, adsorvente comumente empregado para o tratamento de efluentes têxteis. Estes resíduos, após serem utilizados como adsorvente, poderiam ser eliminados pelos métodos descritos.

Cabe ressaltar que o emprego do couro "wet blue" residual como adsorvente não polui o meio aquoso por possível lixiviação do cromo.

\section{AGRADECIMENTOS}

À URI-Campus Erechim, ao Curtume AUREA, a E. Skovroinski, NEWCO, FAPEMIG e CNPq pelo apoio financeiro e à P. Mendes (UFLA-MG) pelas estruturas dos corantes.

\section{REFERÊNCIAS}

1. http://www.qmc.ufsc.br/qmcweb, acessada em Março 2004

2. Guaratini, C. I.; Zanoni, M. V. B.; Quim. Nova 2000, 23, 71.

3. Acântora, M. R.; Daltin, D.; Quim. Nova 1996, 19, 320.

4. Weber, E. J.; Stickney, V. C.; Water Res. 1993, 27, 63

5. Zanoni, M. V. B.; Carneiro, P. A.; Ciência Hoje 2001, 29, 61

6. Bertazzoli, R.; Pelegrini, R.; Quim. Nova 2002, 25, 477.

7. Kapdan, I. K.; Kargi, F.; McMullan, G.; Marchant, R.; Environ. Technol. 2000, 21, 236.

8. Knapp, J. S.; Zhang, F.; Tapley, K.; J. Chem. Technol. Biotechnol. 1997, 69, 289.

9. Houk, V. S.; Water Res. 1992, 277, 201.

10. Kunz, A.; Peralta-Zamora, P.; Moraes, S. G.; Durán, N.; Quim. Nova 2002, 25, 78 .

11. Masten, S. T.; Davies, S. H. R.; Environ. Sci. Technol. 1994, 28, 181 A.

12. Kunz, A.; Freire, R. S.; Rowedler, J. J. R; Mansilla, H.; Rodriguez, J. Rurán, N.; Quim. Nova 1999, 22, 425.

13. Lin, S. H.; Liu, W. Y.; Environ. Technol. 1994, 15, 299.

14. Peralta-Zamora, P.; Kunz, A.; Moraes, S. G.; Pelegrini, R.; Moleiro, P. C.; Reyes, J.; Durán, N.; Chemosphere 1999, 38, 835.

15. Legrini, A.; Oliveros, E.; Braun, A. M.; Chem. Rev. 1993, 93, 671.

16. Vinodgopal, K.; Wynkoop, D. E.; Kamat, P. V.; Environ. Sci. Technol. 1996, $30,1660$.

17. Poulios, I.; Aetopoulou, I.; Environ. Technol. 1999, 20, 479.

18. Costa, R. C. C.; Lelis, F.; Oliveira, L. C. A.; Fabris, J. D.; Ardisson, J. D.; Rios, R. R. A.; Silva, C. N.; Lago, R. M.; Catal. Commun. 2003, 4, 525.

19. Smith, B.; Koonce, T.; Hudson, S.; Am. Dyest. Rep. 1993, 10, 18.

20. Al-Degs, Y.; Khraisheh, M. A. M.; Allen, S. J.; Ahmad, M. N.; Water Res. 2000, 34, 927 .

21. Oliveira, L. C. A.; Rios, R. V.; Fabris, J. D.; Sapag, K.; Lago, R. M.; Carbon 2002, 40, 2177.

22. Oliveira, L. C. A.; Rios, R. V.; Fabris, J. D.; Sapag, K.; Garg, V.; Lago, R. M.; Appl. Clay Sci. 2002, 803, 1.

23. Nassar, M. M.; Proc. Int. Meet. On Chemical Engineering and Biotechnology, ACHEMA-94, Frankfurt, 1994.

24. Nassar, M.; Magdy, Y. H.; Chem. Eng. 1997, 66, 223.

25. Asfour, M.; Nassar, M. M.; Fadali, O. A.; EL-Geundi, M. S.; J. Chem. Technol. Biotechnol. 1991, 50, 257.

26. McKay, G.; Allen, S. J.; J. Sep. Process Technol. 1983, 4, 1.

27. Nicolet, L.; Rott, U.; Water Sci. Technol. 1999, 40, 191.

28. Brown, E. M.; Taylor, M. M.; Marmer, W. N.; J. Am. Leather Chem. Assoc. 1996, 91,270

29. Guardini, G.; US pat. 4,483,829 1983.

30. Imai, T.; Okamura, H.; J. Am. Leather Chem. Assoc. 1991, 86, 281.15.

31. Godinho, M.; Marcilio, N. R.; Masotti, L.; Martins, C. B.; Revista do Couro 2002, Ed 153, 44.

32. Godinho, M.; Marcilio, N. R.; Masotti, L.; Martins, C. B.; Revista do Couro 2002, Ed. 153, 48.

33. Godinho, M.; Marcilio, N. R.; Masotti, L.; Martins, C. B.; Resumos do XVI Encontro Nacional dos Químicos e Técnicos da Indústria do Couro, Paraná, Brasil, 2003.

34. Gregg, S. J.: Sing, K. S.W.; Adsorption, Surface Area and Porosity, $2^{\text {nd }}$ ed., Academic Pree, Inc.: Florida, 1982.

35. Kimura, I. Y.; Gonçalves Jr., A. C.; Stolberg, J.; Laranjeira, M. C. M.; Fávere, V.T.; Polímeros 1999, 9, 1 .

36. Hoinacki, E.; Gutheil, N. C.; Peles e Couros: origens, defeitos e industrialização, CIENTEC: Porto Alegre, 1978.

37. Oliveira, L. C. A; Dallago, R. M.; Petkowiczs, D.; Smaniotto, A.; Water Res., submetido. 